\title{
Entrevista com Harry Crowl
}

\author{
Harry Crowl, Antonio R. Spoladore Hurtado \\ Universidade Federal do Paraná | Brasil
}

\begin{abstract}
Resumo: a presente entrevista trata da preservação e do processo composicional da obra Convivium (1986), do compositor Harry Crowl. A obra foi composta em fita magnética, fator que dificulta a sua preservação. Através da entrevista, o compositor revela aspectos do processo de preservar uma obra de forma independente, levando em conta as relaçóes entre o processo composicional, o contexto sócio-político em que foi criada e a mídia que foi utilizada para armazená-la. Com base nessas relaçóes, torna-se possível digitalizar a obra com o intuito de preservá-la. Além disso, a entrevista trata de alguns detalhes das condiçóes de trabalho da maioria dos compositores de música eletroacústica no Brasil na década de 1980, possuindo, portanto, uma importância musicológica.
\end{abstract}

Palavras-chave: música eletroacústica, preservação em música, documentação, composição musical, música contemporânea.

\begin{abstract}
: the present interview is about the preservation and the compositional process of Convivium (1986), by the composer Harry Crowl. The piece was composed on magnetic tape, which is a factor that makes its preservation difficult. The composer reveals aspects of the process of preserving a musical work as an individual, taking into account the relations between the compositional process, the socio-political context in which it was created and the media that was used to record it. Based on these relations, it becomes possible to digitize the original piece on an updated media in order to preserve it. In addition, the interview deals in some details about the working conditions of most composers of electroacoustic music in Brazil in the 1980s, therefore this interview has a musicological relevance.
\end{abstract}

Keywords: electroacoustic music, musical preservation, documentation, musical composition, contemporary music. 


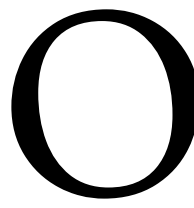

compositor e musicólogo brasileiro Harry Crowl (1958 -) estudou Música, Letras e Semiótica no Brasil e Composição na Juilliard School of Music, nos Estados Unidos. Em seu catálogo constam aproximadamente 200 obras musicais, dentre as quais há todos os gêneros instrumentais e vocais, incluindo música para cinema e teatro. Entretanto, há apenas uma obra puramente eletroacústica em seu catálogo: Convivium, de 1986. A ideia de criar a obra surgiu a partir da participação do compositor em uma oficina de composição eletroacústica com o compositor argentino Eduardo Bertola na cidade de Ouro Preto.

A música eletroacústica surgiu no Brasil através de um esforço de compositores que, mesmo com diversas limitações técnicas e pouco apoio institucional, desenvolveram seus trabalhos no país (LEITE, 2000, p. 11). Durante a década de 1980, período em que a obra de Harry foi composta, já havia no país pessoas capacitadas, cursos voltados à música eletrônica (RODRIGUES, 2015) e muitas vezes os compositores precisavam compor com as ferramentas que estivessem disponíveis, mesmo que limitadas. Essas limitaçóes foram incorporadas no processo composicional e até mesmo na estética de obras eletroacústicas e foi neste contexto que Harry Crowl compôs sua peça em fita magnética.

Dentro deste contexto de limitaçóes, vemos hoje a necessidade da preservação, que gera preocupação tanto para os compositores quanto para as instituiçôes. Mesmo com a Tape Music, ou seja, quando a música é inscrita em mídia fixa, a preocupação é genuína, visto a grande variedade e rápida obsolescência das mídias, dos processos e dos equipamentos de áudio (CANAZZA; VIDOLIN, 2001, p. 289). A digitalização é tida como a forma mais segura de preservação atualmente, sendo o formato wave com taxa de amostragem de $48 \mathrm{kHz}$ ou $96 \mathrm{kHz}$ e resolução de 24bit o padrão técnico estabelecido em arquivos digitais (RESÉNDIZ, 2016, p. 204). Contudo, para serem digitalizadas, as fitas precisam estar em boas condições de armazenamento, visto que a falta de cuidados pode deteriorar ou até mesmo destruir estas mídias - problema grave que já foi responsável pela perda definitiva de obras por todo o mundo (CANAZZA; VIDOLIN, 2001, p. 289).

Portanto, a fita magnética é uma das mídias de mais difícil preservação por conta de sua fragilidade e dos problemas que podem decorrer disso. Para serem bem preservadas, precisam ser armazenadas na vertical, em locais secos a uma humidade relativa de $40 \% \pm 5 \%$ e a uma temperatura de $20^{\circ} \mathrm{C} \pm 3^{\circ} \mathrm{C}$ (SCHÜLLER 2007 apud NOGUEIRA et al., 2015, p. 262). Além disso, para digitalizar é necessário compreender também a estética da obra, para que haja discernimento entre o 
que é ruído dos equipamentos ou deterioração da mídia e aquilo que faz parte da música (BARI et al., 2001, p. 351).

Ademais, frisamos um outro importante aspecto da música eletroacústica hoje em que muitos compositores assumem a responsabilidade de preservação de sua própria música. Isso se dá por conta do baixo incentivo político e institucional na criação e manutenção de acervos de música eletroacústica, especialmente no Brasil, da dificuldade para a preservação e, por consequência, da grande quantidade de obras que estão em processo de deterioração - que por conta disso se tornam grandes demandas prioritárias para os acervos. Dentro deste cenário, temos na obra Convivium, de Harry Crowl, um exemplo de obra preservada pelo próprio compositor. A obra composta entre 1985 e 1986 já possui cópia digitalizada desde 1996 e a fita original está em posse do compositor. É nesse contexto que realizamos a seguinte entrevista com Harry Crowl acerca do processo criativo de sua obra e das preocupações em torno de sua preservação (entrevista realizada com o compositor via plataforma ZOOM na data de 21/12/2020).

Antonio Spoladore: Gostaria de começar perguntando sobre o seu processo composicional: como foi que você fez? Quais foram os equipamentos utilizados? Quais foram os sons que você utilizou?

Harry Crowl: A minha preocupação, no primeiro momento, era usar esses sons de origem étnica, como definiram na época, ligados a países e culturas do chamado Terceiro Mundo. Queria fazer um trabalho criando sons a partir dessas gravaçóes originais recolhidas que tivessem pontos em comum e então faria um grande painel com isso. Também usaria, em alguns momentos, sons eletrônicos para poder fazer pontes, ou vamos dizer, para amalgamar o material de uma forma mais bem acabada. Minha preocupação foi essa. Eu dispunha de equipamentos muito limitados. Fiz uma oficina de música eletroacústica com o Eduardo Bertola, compositor argentino que morava no Brasil, e ele já estava em Belo Horizonte há muitos anos. O Bertola foi um militante da causa da música contemporânea latino-americana, muito ativo, principalmente da música eletroacústica por meios pobres. Havia toda uma corrente em países como Argentina e Uruguai de se fazer música eletroacústica com o mínimo de recursos possível. Senti muito interesse por esse movimento. Eram 
movimentos estéticos meio clandestinos que surgiram nos períodos das ditaduras militares nesses países. No Brasil, isso também aconteceu. Só que parece que a repressão nesses países foi maior. Eles tiveram como ponto de partida o cinema novo brasileiro. Era curioso ver que o cinema de Glauber Rocha tinha um impacto na Argentina e no Uruguai bem maior do que aqui no Brasil. Os compositores captaram isso. Eles ficaram muito impressionados com a concisão do Glauber Rocha, essa coisa de fazer filme só com uma câmera na mão. Começaram a tentar fazer isso com o processo de composição eletroacústica. Me lembro do Eduardo Bertola lá em Belo Horizonte, na Fundação de Educação Artística, dando curso sobre isso. Cada um trazia o equipamento que podia. Me lembro de colaborar com um equalizador analógico. Enfim, ele tinha os equipamentos dele. Tinha um Nagra, que era um gravador de rolo que eu só tinha visto com equipes de filmagem. Aquilo era altamente profissional. Era um gravador de pista inteira e o material original recolhido foi todo gravado em fitas nesse Nagra, para depois ser passado e trabalhado em cima dos gravadores Akai. Em princípio, era um material que ele tinha conseguido copiar de matrizes originais, não eram necessariamente cópias de discos de vinil só. Ele tinha algum material original que tinha conseguido da Unesco, em Paris. Então, selecionei a partir desses materiais. Eu tinha alguma coisa em casa copiada de vinil, mas já em fita cassete - porque não eram discos meus, mas, como achei interessante, copiei de diversas fontes - fui fazendo a seleção desse material. Claro, foi algo muito trabalhoso, porque eu já percebia que quanto mais eu passasse a gravação de um lado para o outro, ou seja, gravava uma vez, gravava outra vez em cima, a qualidade ia caindo rapidamente. Então, fiz alguns exercícios nas oficinas com ele: por exemplo, eu aprendi a fazer edição de fita a mão mesmo. Não tínhamos nem aqueles trackers, que são aquelas pequenas formas de metal para colocar fita em cima e fazer um corte preciso. Não, era só na tesoura desmagnetizada. A gente conseguia com dificuldade comprar essa fita magnética de edição da própria Scotch (marca de fitas adesivas). Foi um trabalho muito manual, artesanal mesmo.

AS: Esse trabalho dialoga com a poética da obra (do "grito" do Terceiro Mundo)?

HC: Talvez a minha própria ideia de construção da peça tenha sido influenciada pela pelo processo técnico. Como eu sabia que eu ia ter que lidar com isso, não existia computadores - estamos falando da década de 1980, então, não existia nem internet e nem computador pessoal. Pois, isso é coisa dos 
anos de 1990. Eu sabia que ia ter à minha disposição somente equipamentos analógicos. Não existia nenhum laboratório de música eletroacústica que em $\mathrm{BH}$ tivéssemos conhecimento. Sobre isso, ouvíamos falar das rádios na Europa e através de fotografias, tínhamos alguma noção. O Bertola contava como era. Mas, na prática, o que tínhamos de mais profissional e sofisticado era o gravador Nagra dele para gravarmos algum material e fazer a manipulação de alguma coisa. Tive que concluir esse trabalho depois nos gravadores Akai semiprofissionais lá da UFOP (Universidade Federal de Ouro Preto).

AS: Já tocando no assunto da preservação, desde o começo você já pensava em preservar esse material original?

HC: Esse assunto da preservação para mim é bem particular. Nessa época, estava interessado em música eletroacústica e vivendo em Ouro Preto, trabalhando com pesquisa de música do período colonial e fazendo transcrições de música do final do século XVIII e início do século XIX, coisas que eram aparentemente opostas. Esta coisa da manutenção, da preservação da matéria musical fora do papel me chamava a atenção. Embora o papel seja frágil também, os próprios acervos de música do período colonial mostram isso: muitos manuscritos ficaram expostos à umidade por tanto tempo que a escrita musical praticamente se desmanchou. Eu ficava pensando em como fazer com a fita magnética, pois Ouro Preto é uma cidade muito úmida. O mofo cresce em qualquer lugar. É uma coisa quase impossível de se controlar. Já percebia com as minhas fitas cassete. Elas soltavam muito óxido nos cabeçotes dos gravadores e isso me deixava preocupado. Não conseguia fitas de rolo de boa qualidade, até que eu cruzei com o Djalma Correia, percussionista. Ele me deu uma fita profissional de alta resistência da marca Sony. Isso foi o que me deixou bastante aliviado. Então, usei essa fita para guardar o trabalho final e procurei sempre mantê-la em ambiente o mais seco possível. Como essa fita já está aqui em Curitiba há 23 anos mais ou menos, sempre procurei mantê-la em um lugar totalmente protegido; e isso foi o que o que ajudou na preservação. Sempre tive essa preocupação e lendo a respeito, as vezes que procurei informação, percebi que era uma preocupação legitima. Estive em alguns festivais de música contemporânea na Europa com apresentação de concertos históricos, como o laboratório da Rádio de Colônia, que promoveu um concerto na Fundação Gulbenkian, em Lisboa, em homenagem ao Luigi Nono. Era todo um festival em 
homenagem ao Nono, em 1995. Achei muito curioso, porque eles trouxeram toda uma tralha, uma quantidade de aparelhos gigantescos, umas estruturas de alumínio bem artesanais. Aquilo tudo precisava de uma equipe de quase 20 pessoas para fazer funcionar. Era um concerto-museu. Eles estavam querendo passar a ideia para o público do que era fazer essa música eletroacústica nos anos 50 e, para preservar isso, eu vi que há um investimento pesado. Não é fácil. Há, também, uma relação bem estreita com a área da museologia.

AS: Nas suas obras instrumentais também houve essa preocupação com a preservação desde o início? Ou foi algo que começou com o seu trabalho de resgate de repertório colonial?

HC: Com a música escrita, ainda sou da época de quem tende a achar que o papel é mais perene, essa preocupação é menos aparente. Porém, sempre guardei com muito cuidado, também procurando preservar, manter os manuscritos longe de qualquer umidade. Só que daí surgiu um outro problema: a partir de 2006, comecei a trabalhar diretamente com o programa de edição de partituras, o Finale. Então, assim, não fiz mais obras inteiras em manuscritos. Tenho vários esboços, mas a versão final é toda digital. Daí, já surgiu outra preocupação: como ter uma preservação absoluta disso? Devo pegar todas as obras que fiz já com o programa no computador e imprimir para guardar, além de ter o backup da obra em locais diferentes? De qualquer maneira, o tempo tem mostrado que a preservação do acervo digital ainda não causa nenhum problema. Tenho cópias bem antigas. Tenho algumas obras que não fui eu que fiz, que foram pessoas que eu contratei para fazer partituras em formato digital, na década de 1990. O meu Concerto para piano e orquestra, de 1997, é um exemplo. Já fiz algumas interferências, o sistema digital permite que eu possa abrir a partitura com o programa atualizado - ele já me leva automaticamente para nova versão do Finale - e se eu quiser mexer em alguma coisa, também posso mudar o layout, fazer uma revisão, mexer nas notas, em tudo. Tudo está aberto à intervenção. Enfim, a preocupação ainda existe, e sempre vai existir, eu acho. Hoje, vejo que a segurança por estar no papel não é tão grande. Tenho cópias dos arquivos em HD externo e no computador. Ainda não estou com muita confiança na nuvem, mas tenho algumas coisas lá. 
AS: Voltando à sua obra de 1986, Convivium, já tinha sido feita uma digitalização dela, correto?

HC: Sim, foi feita lá no Laboratório de Pesquisas Sonoras da PUC de São Paulo, dentro do curso de Comunicação e Semiótica - que já não tem mais esse nome. Eles criaram um laboratório, fiz mestrado lá. Então, levei a fita de rolo e fiz uma transcrição para o sistema digital em uma fita DAT, já aplicando alguns recursos que eram possíveis, como a re-equalização, na base da tentativa e erro.

AS: Em relação à qualidade do som, você acha que a versão digitalizada mudou muito em relação à ideia original, por conta da ausência do "calor" do equipamento analógico e da fita? Esse calor fazia parte da peça?

HC: O que acontece é o seguinte: no sistema digital é mais fácil manipular as coisas, evidentemente. Então se quisermos mascarar algum efeito, introduzir alguma informação, algum som artificial de senóide, de onda quadrada ou de onda serrilhada, fica muito mais fácil. Porém, o que percebi nessa versão que você me mandou da cópia feita diretamente da fita original, o som analógico é muito mais quente, muito mais agradável de ouvir. Para mim, há uma carga emocional contida na obra que tende a desaparecer um pouco na versão digital.

AS: (...)E isso dialoga bastante com a poética da peça...

HC: Sim.

AS: Em relação às manipulações que você fez com os arquivos, principalmente com os arquivos da coleção da Unesco, quais os processos você poderia destacar?

HC: Trabalhei com alterações de velocidades, sobreposições de fontes diferentes, retrogradações usei bastante o recurso de tocar fita de trás para frente -, retrogradações com alteração de velocidade, algumas imbricações também - decrescendo e subindo a dinâmica, e outra voz entrando em "pp" e crescendo para o "f”. Basicamente isso, não tinha muito além disso para fazer. Fazia vários testes primeiro, várias improvisaçôes, para depois gravar. Peguei sons de disco de vinil também, 
porque, principalmente, como já disse, eu não tinha acesso aos sons de origem eletrônica propriamente dita. Então tentei recortar isso de outras obras que percebia que tinha um som que se aproximava do que eu queria. Os toca-discos tinham duas possibilidades de velocidade, 33 RPM e 45 RPM. Às vezes, usei aceleração de 33 para 45 quando sentia necessidade. Se eu conhecesse a técnica dos DJs, teria feito mais coisas [risos]. Segurando o prato do toca-discos; e depois soltando, como eles fazem com um virtuosismo enorme, mas na época não me ocorreu isso. Nunca tinha visto; e não me passou pela cabeça.

AS: O processo composicional de "Convivium" durou quanto tempo?

HC: Foi longo. Mais de um ano. Eu fazia, refazia. Para chegar no resultado final - para eu dizer que estava pronto, e que não iria mexer mais - foram quase dois anos. Algo como do início de 1985, por volta de fevereiro ou março, até o final de 1986.

AS: Esse foi um dos fatores de você não ter mais usado recursos eletrônicos depois disso? Essa é sua única peça inteiramente eletrônica, não?

HC: Sim. Tem duas coisas. Uma é que eu fiquei muito feliz com o resultado. Não conseguia me ver retomando uma peça eletroacústica desde o início. Realmente não via a possibilidade de superar aquele resultado. É claro que também achei muito trabalhoso e cansativo, sentia mais atração pela música puramente acústica e também tinha outra coisa. Um problema que me acompanhou a vida quase toda com a música eletrônica, eletroacústica, concreta e todas as suas formas que vieram depois: certos clichês me incomodavam, como o excessivo uso de sons contínuos e essa técnica de ir sobrepondo mais sons aos sons contínuos. Aquilo dali me servia em certos momentos, mas não todo o tempo. Me lembro que no ano 2000, em Curitiba, houve um encontro internacional de música eletroacústica organizado pela SBME (Sociedade Brasileira de Música Eletroacústica). O evento aconteceu em um auditório da PUC Paraná, com bons recursos para isso. Então foram organizadas, num primeiro momento, três longas apresentaçôes de música eletroacústica. Uma delas teve que ser cancelada por causa de um congresso que aconteceria no mesmo espaço. Com isso, ficaram apenas dois concertos com a duração de quase 4 horas cada um. Lembro-me que era em um 
inverno muito rigoroso; e fazia um frio tremendo. Dei-me conta que realmente aquilo não era a minha praia. Estava na moda a síntese granular; e acho que dois terços das obras eram à base de síntese granular. Ou eram músicas feitas com esses sons contínuos com sobreposições, ou inteiramente baseadas em síntese granular. Já era música totalmente feita com computador, aí eu já percebi que aquilo não era meu negócio. Nos festivais internacionais em que estive, sempre havia alguma apresentação de música eletroacústica. Chamava-me a atenção o fato que os meios estavam mudando muito rapidamente, por causa do avanço da tecnologia, mas do ponto de vista da linguagem, os resultados continuavam ainda muito rudimentares para mim. Eu ficava pensando, o Canto da Juventude (Gesang der Jünglinge), do Stockhausen feito lá no início dos anos de 1960 ainda soava para mim, esteticamente mais avançado que a maioria das peças.

Paralelamente, sempre compus muito música acústica. Sempre fui emendando a criação de uma obra na outra. Teve época em que escrevia várias obras simultaneamente.

AS: $\mathrm{Na}$ sua peça, esteticamente, tem algumas ideias que que vão de encontro à música concreta, mas eu acho que dialoga também com esse conceito atual de colagem sonora. O que você diria sobre isso?

HC: É um processo de colagem, sim. Conhecia muito pouco a música concreta na época. Sabia do que se tratava, mas na prática não tinha ouvido quase nada. A ideia era certamente de colagem. Era a colagem do som que está ali de uma forma concreta, ou seja, identificável, mas que perde esse contorno de definição e torna-se outra coisa. E isso era o que mais me atraía. Chamou-me a atenção ouvindo a peça agora que eu acabei por escolher fontes sonoras majoritariamente do Hemisfério Sul. Basicamente aqueles sons todos são da África, da América do Sul e da Ásia, sendo que os da Ásia eram mais da parte do Sudeste Asiático: sons das Filipinas e da Indonésia, próximos ao Equador. Os sons mais ao norte são uns cantos rituais tibetanos e os sons das trombetas. Tive o cuidado ali de excluir qualquer som da tradição ocidental. Apenas alguns servem como um amálgama; para ajudar a fundir uma ideia na outra.

AS: Você chegou a utilizar algum som de origem brasileira? 
HC: Cantos indígenas, das mulheres do Xingu. Elas aparecem várias vezes, ora na versão original, ora aparecem sobrepostas.

AS: Se você tivesse feito essa peça hoje, o que você faria para preservá-la?

HC: Hoje nem me passaria pela cabeça usar fita magnética como suporte. Se eu lançasse essa obra em algum suporte físico, já seria uma maneira de preservá-la. Se fizesse um CD ou um DVD, por exemplo. Há um formato que não colou muito aqui no Brasil, mas que no norte da Europa; ganhou uma certa força: o SACD (Super Audio CD), que tem uma perspectiva muito interessante. São só dois canais, mas com tridimensionalidade, ou seja, é um CD no qual só se percebe os seus efeitos quando se ouve em um aparelho de DVD ou então, no próprio reprodutor de SACD, que atualmente acho que só é fabricado na Suécia. Dá para se perceber com muita nitidez em que ponto estavam os instrumentos no momento da gravação. Ele permite uma emulação de espaço muito grande, no sentido de uma maior profundidade - percebe-se qual instrumento está na frente, no meio, ao fundo. Pensaria em algo assim. Um suporte para difusão maior, não sei, porque na verdade são nuvens de dados, não tem como escapar. Em sua maioria, os CDs da primeira geração, os da década de 1980, está com problemas. Descobriram uma solução para isso já nos anos de 1990. De lá para cá, parece que está tudo bem. O tipo de material usado para fazer a lâmina central corroía-se com o tempo. Conseguiram, finalmente, que o CD venha $100 \%$ encapsulado, ou seja, a resina plástica que envolve o CD não expõe nenhum ponto da película metálica. A película é feita de um metal muito especial que é praticamente usado só para isso. Já joguei fora CDs dos anos 80, pois já não havia o que fazer com eles. Começaram a aparecer pequenos orifícios na película e a informação se perdeu por completo.

\section{REFERÊNCIAS}

BARI, Andrea; CANAZZA, Sergio; DE POLI, Giovanni; MIAN, Gian Antonio. Toward a methodology for the restoration of electroacoustic music. Journal of New Music Research, v. 30, n. 4, p. 351-363, 2001.

CANAZZA, S.; VIDOLIN, A. Introduction: preserving electroacoustic music. Journal of New Music Research, v. 30, n. 4, p. 289-293, 2001. 
LEITE, Vânia. Musicians and movements that initiated electroacoustics in Brazil. In: SIMPÓSIO BRASILEIRO DE COMPUTAÇÃO E MÚSICA, 7, 2000, Curitiba. Anais do XX Congresso Nacional da Sociedade Brasileira de Computação. Curitiba, 2000. Disponível em: $<$ http://compmus.ime.usp.br/sbcm/2000/papers/leite.pdf $>$. Acesso em: 24 mar. 2021.

NOGUEIRA, Andreia; MAGALHÃES, Filipa; PIRES, Isabel; MACEDO, Rita. A preservação da performance musical contemporânea: o caso do espólio fonográfico em fitas magnéticas de Clotilde Rosa. In: PROCESSOS DE MUSEALIZAÇÃO: UM SEMINÁRIO DE INVESTIGAÇÃO INTERNACIONAL, 2014, Porto. Atas do Seminário. Porto: Universidade do Porto, 2015, p. 252 268.

RESÉNDIZ, Perla. El OAIS en la preservación digital de archivos sonoros. Investigación Bibliotecológica, v. 30, n. 70, p. 197-220, 2016.

RODRIGUES, Henderson. Música eletroacústica no Brasil. Formação musical, 2015. Disponível em: $<$ https://hendersonpessoal.wordpress.com/2015/03/08/musica-eletroacustica-no-brasil/>. Acesso em: 5 mar. 2021.

\section{SOBRE OS AUTORES}

Harry Crowl (1958 -) é compositor e musicólogo radicado em Curitiba desde 1994. Tem formação em Música, Letras e Semiótica no Brasil, e nos EUA, estudou composição na Juilliard School of Music. Foi Professor da Escola de Música e Belas Artes do Paraná/UNESPAR até 2019. É Diretor Artístico da Orquestra Filarmônica da UFPR. Entre os prêmios recebidos destacam-se, "Encomenda de Obra”, 2012 e 2014, da FUNARTE, para os quais escreveu "Mirabilis Jalapa”, estreado na XXa. Bienal de Música Brasileira Contemporânea, no Rio de Janeiro, em 2013, e; “Elogio da Sombra”, para clarone e orquestra de cordas, estreada na XXIa. Bienal, em 2015. E-mail: harrycrowl@uol.com.br

Antonio R. Spoladore Hurtado (1996 -) é mestrando na área de Composição Musical pela Universidade Federal do Paraná (UFPR), sob orientação de Felipe de Almeida Ribeiro. Possui graduação em Produção Sonora e Criação Musical, também na Universidade Federal do Paraná, no ano de 2018. Desenvolve pesquisas sobre composição musical, música eletroacústica e áudio, com ênfase em processos composicionais e preservação e performance de música eletroacústica. Estudou composição com Felipe Ribeiro, Roseane Yampolschi, Clayton Mamedes, Indioney Rodrigues e Maurício Dottori. Atua como compositor, produtor musical, guitarrista, professor e pesquisador. ORCID: https://orcid.org/0000-0003-0474-582X. E-mail: antoniospoladore.hurtado@gmail.com 